\title{
Transference interpretations as predictors of increased insight and affect expression in a single case of long-term psychoanalysis
}

\author{
Yasemin Sohtorik İlkmen, ${ }^{1}$ Sibel Halfon ${ }^{2}$ \\ ${ }^{1}$ Department of Psychology, Boğaziçi University, Bebek, Istanbul; ${ }^{2}$ Department of Psychology, Bilgi University, Istanbul, Turkey
}

\begin{abstract}
Improved insight and affect expression have been associated with specific effects of transference work in psychodynamic psychotherapy. However, the micro-associations between these variables as they occur within the sessions have not been studied. The present study investigated whether the analyst's transference interpretations predicted changes in a patient's insight and emotion expression in her language during the course of a long-term psychoanalysis. 449 thematic units from 30 sessions coming from different years of psychoanalysis were coded by outside raters for analyst's use of transference interpretations using Transference Work Scale, and patient's insight, positive emotions, anger and sadness were calculated using the Linguistic Inquiry and Word Count System. Multilevel modeling analyses indicated that transference interpretations positively predicted patient's insight and positive emotion words and negatively predicted anger and sadness. The qualitative micro-analyses of selected sessions showed that the opportunity to explore negative emotions within the transference relationship reduced the patient's avoidance of such feelings, generated insight into negative relational patterns, and helped form more balanced representations of self and others that allowed for positive feelings. The findings were discussed for clinical implications and future research directions.
\end{abstract}

Key words: Transference interventions; Insight; Emotions; Empirical case study.

Correspondence: Yasemin Sohtorik İlkmen, Department of Psychology, Boğaziçi University, Bebek, Istanbul, 34340, Turkey. Tel. +90.212.359.7055.

E-mail: sohtorik@boun.edu.tr -ysohtorik@yahoo.com

Citation: Sohtorik İlkmen, Y., \& Halfon, S. (2019). Transference interpretations as predictors of increased insight and affect expression in a single case of long-term psychoanalysis. Research in Psychotherapy: Psychopathology, Process and Outcome, 22(3), 427-438. doi: 10.4081/ripppo.2019.408

Acknowledgments: the authors thank Dilan Şenlik and Hande Deveci for their contribution in data coding.

Contributions: the authors contributed equally.

Conflict of interest: the authors declare no potential conflict of interest.

Funding: none.

Received for publication: 3 May 2019.

Revision received: 26 June 2019.

Accepted for publication: 18 July 2019.

This work is licensed under a Creative Commons Attribution NonCommercial 4.0 License (CC BY-NC 4.0).

${ }^{\circ}$ Copyright: the Author(s), 2019

Licensee PAGEPress, Italy

Research in Psychotherapy:

Psychopathology, Process and Outcome 2019; 22:427-438

doi:10.4081/ripppo.2019.408

\section{Introduction}

The role of transference, as the repetition of repressed historical past in a new context with the therapist, has been recognized as an essential element of psychoanalytic therapies since Freud formally introduced the term in 1912. Freud initially thought transference was a form of resistance and disrupts the progress of analysis. As his theories on therapy and technique evolved over time, he considered the analysis of transference to be the most effective element of psychoanalytic treatment (Gay, 1988). Consequently, transference became a means to understand and translate the unconscious, and transference interpretations the necessary and primary components of analytic technique by fostering insight. Through this process the patient gains insights into their relationship patterns, and gets a chance to experience a different type of relating with the therapist who provides the conditions to achieve this change (Heimann, 1956). More recently, clinicians and researchers started to rely on broader definitions of transference, not solely as enactment of early relationships but also as a new experience influenced by the relationship with the therapist (Cooper, 1987). Transference interpretations in most empirical studies are defined as an explicit focus on the here-and-now relationship between the therapeutic dyad and links to earlier relationships (Hoglend, 1993, 2004; Piper, Azim, Joyce, \& McCallum, 1991). According to psychodynamic theory, transference interpretations are an essential component of psychodynamic technique because of their effectiveness in increasing insight about the nature of the 
one's problems and in their immediate affective resonance to the patient as they are practiced in the here and now of the therapeutic relationship (Gabbard \& Westen, 2003; Messer \& McWilliams, 2007). However, linking hereand-now issues to earlier experiences is not always necessary, and actually not recommended for patients with severe personality disorders (Levy \& Scala, 2012). For instance, in Transference Focused Psychotherapy developed particularly for patients with borderline personality disorder, interpretations are utilized to address the present unconscious particularly in the earlier phases of the treatment (Kernberg, 2016).

Despite this central position of transference interpretations in psychodynamic therapies, there is conflicting research evidence regarding the relationship between transference interpretations and treatment outcome. Whereas some research shows a direct association between transference interpretations and outcome (i.e., Clarkin, Levy, Lenzenweger, \& Kernberg, 2007; Doering et al., 2010; Levy et al., 2006), others fail to report such an association (i.e., Hoglend, 1993; Piper et al., 1991). These null findings suggest that rather than a direct association between transference interpretations and outcome, this relation may be mediated by other mechanisms of change, particularly increased affect expression, tolerance, and insight (Johansson et al., 2010; Høglend \& Hagtvet, 2019). There is converging research evidence that shows that gains in insight on one's problems during psychodynamic treatment are associated with successful outcome (Grande, Rudolf, Oberbracht, \& Pauli-Magnus, 2003; Johansson et al., 2010; Kivligham, Multon, \& Patton, 2000) and these results are further strengthened when this is combined with emotional expression (Fisher, AtzilSlonim, Barkalifa, Rafaeli, \& Peri, 2016; Kramer, Pascual-Leone, Despland, \& de Roten, 2015; Solbakken, Hansen, \& Monsen, 2011) creating a cognitive-emotional processing that would not be possible without either component. It is possible that these change mechanisms are best activated within the transference relationship, where a cognitive-affective restructuring takes place in the here and now of an affectively charged relationship and interventions help the patient to gain insight on his/her own internal world and relationship patterns (Kernberg, Diamond, Yeomans, Clarkin, \& Levy, 2008). Following these findings, the aim of this study was to investigate the associations between transference interpretations and a patient's changes in emotion expression and insight as expressed in her language in a single case of long-term psychoanalysis.

\section{Transference interpretations and mechanisms of change in psychodynamic therapies}

The association between transference interpretations, affective resonance and insight has been empirically investigated in few research studies. Johansson et al. (2010) found in a randomized clinical trial that the effect of trans- ference interpretations on interpersonal and overall functioning was mediated by increased insight. In another study, Ulberg, Amlo, Johnsen Dahl, and Hoglend (2017) demonstrated on two clinical cases that transference interpretations were associated with improved therapy outcome by enhancing insight. Investigating the mechanisms of change, Messer (2013) demonstrated the positive impact of insight achieved through transference interpretations in a single case study. However, insight needs to be linked to appropriate affect in order for working through to take place (Gabbard \& Westen, 2003). To the authors' knowledge, only Høglend and Hagtvet (2019) investigated whether increased affect awareness along with insight mediated the relation between initial functioning and outcome and found support for this model long-term transference focused work.

Contemporary psychoanalytic theories emphasize the importance of the corrective emotional experience within the therapeutic relationship as an essential element of change (Gabbard \& Westen, 2003). These relational theories regard human psych as emerging within a relational context in which intrapsychic and interpersonal aspects continually shape each other (Mitchell, 1988). One of the central themes in the relational theories is the interaction between transference and countertransference, and how they influence each other (Aron, 2006). In these views, both analyst and patient contribute to the analytic interaction. The insights gained in therapy are considered specific to the particular analyst-patient dyad because they are co-created by this analytic couple (Renik \& Spillius, 2004). Since both parties bring their own subjective experiences to this interaction, they both contribute significantly in the co-creation of the patient's understanding of his/her mental life. In this intersubjective view of the clinical encounter both participants must mutually recognize each other's subjectivity in order to achieve separation, awareness of the outside reality and ability for attunement with the other (Benjamin, 1990). However, recent theories suggest that therapeutic change is facilitated by both insight and therapeutic relationship as well as their interaction in complex ways (Gabbard \& Westen, 2003).

\section{Linguistic analyses of affect expression and insight}

Traditionally, patient's insight and affect expression have been investigated via self-report scales or observerrated measures, which provide an outside and partial perspective into the immediate experience of the patient in the session. In order to address this problem, computerized linguistic analyses have been employed on session transcripts to understand the psychological, particularly cognitive and affective processes that are associated with patient's word choices. Pennebaker and coworkers have done pioneering work in the study of different word categories and linking these with various psychological states based on their computer based linguistic program named Linguistic Inquiry Word Count (LIWC) (Pen- 
nebaker, Booth, Boyd, \& Francis, 2015a). They have not focused particularly on psychodynamic therapies; however, they extensively analyzed the writing features most strongly associated with enhanced psychological and physiological health and found that it is important for people to generate insight and express affect related to personal experiences, especially ones that are traumatic or stressful (Pennebaker \& Seagal, 1999). In particular, stories that contained a high rate of emotion words (e.g., sad, hurt, guilt, joy) and insight words (e.g., understood, thought, know) showed the greatest benefit (Pennebaker \& Seagal, 1999).

Other studies showed that the valence of emotion words affected different facets of psychological health. For example, using a high frequency of positive emotion words in an expressive writing exercise was associated with improved physical health as indicated by decrease in the number of physician visits and self-report symptoms (Pennebaker, Mayne, \& Francis, 1997). The specific types of negative emotion words also relate to adjustment and can shed light on additional facets of emotional expression. In one study, researchers examined the expression of negative emotions in written texts and found that the expression of anger and sadness were associated with higher quality of life and lower depression scores among breast cancer patients (Lieberman \& Goldstein, 2006).

\section{Computerized linguistic analyses of psychodynamic treatments}

Computerized linguistic analyses of treatment processes provide the means to integrate systematic linguistic analysis of sessions with clinical evaluations. Erhard Mergenthaler and his group focused on the emotional tone (density of emotional words) and level of abstraction (the amount of abstract nouns) within patients' language in psychodynamic therapies and found that successful outcome in psychodynamic therapy is associated with increased use of emotion and abstraction in language, which shows that the patients have emotional access to conflictual themes and can reflect upon them building insight (Buchheim \& Mergenthaler, 2000; Gelo \& Mergenthaler, 2012; Lepper \& Mergenthaler, 2008). Bucci’s multiple code theory is another application of these premises to psychoanalytic research using the concept of Referential Activity (RA; see Bucci, Maskit, \& Murphy, 2016, for a review). Bucci has found that patients initially come to therapy with sensory and somatic emotion schemas not yet associated with words. However, if the treatment is working properly, these schemas are integrated in a narrative, which will include the analyst, sometimes explicitly, almost certainly implicitly and the representations of emotions in the here and now of the therapeutic relationship (Bucci \& Maskit, 2007; Bucci, Maskit, \& Hoffman, 2012). Even though Pennebaker and his group have not particularly studied patients' linguistic choices in psychodynamic treatments, the associations they found between emotion expression and insight in expressive writing tasks have to do with the creation of a narrative that provides a cognitive and affective elaboration of incoherent experiences; an idea that is much akin to the psychoanalytic principles of the talking cure.

In terms of the types of emotions expressed, Mergenthaler (2008) posits that negative emotion occurs first within a session for problems to be elicited followed by an increase in positive emotion for key helpful moments of problem solving to begin. Similarly, Pennebaker and Francis (1996) found that students who used more positive emotion words and words indicating insight and causal thinking when writing about thoughts and feelings had better health outcomes.

Some studies examined how therapists' interventions predicted changes in patient's linguistic choices. For example, Vegas, Halfon, Cavdar, and Kaya (2015) looked at the association between the analyst's interventions and patient's discourse patterns and found that analytic explorations predicted the patient's emotional and insight focused language. Recent literature has begun to examine therapist-patient discourse to identify therapist and patient contributions to significant change processes within therapy (Levitt \& Piazza-Bonin, 2011). In particular, Valdés et al. (2010) found that within change moments patients brought up a number of different emotions and therapists explored these emotions. Valdés Sanchez (2012) found that during change episodes when therapist showed understanding and mirroring of patient's affective states in the here and now and gave new meaning to emotional material, patient presented novel emotional content. Furthermore, patient responded with cognitive insight words in response to therapist's emotional processing of transferential material. These studies indicate that patients respond to therapist's interventions with increased insight and emotion expression in language particularly during change moments. However, to the author's knowledge, there have been no prior studies that specifically assessed the associations between transference interpretations and patient's level of insight and emotion expression in language.

\section{The case of study}

The sessions examined in the current study were taken from a case known as Mrs. C in the psychoanalytic literature and has been studied previously by various researchers (Ablon \& Jones, 2005; Halfon, Fisek, \& Cavdar, 2017; Halfon \& Wenstein, 2013; Jones \& Windholz, 1990). Mrs. C was in psychoanalysis for six years, yielding nearly 1,100 hours of which were all audio-taped (Jones \& Windholz, 1990). Using the Q-technique, Jones and Windholz (1990) examined Mrs. C's analysis, and concluded that the outcome of her analysis was successful. They found that over the course of her treatment, Mrs. C exhibited increased capacity for free association and access to her emotions, greater self-disclosure and decreased amount of intellectualization and rationalization. They 
also reported improvement in her initial complaints of feelings of inadequacy, guilt and anxiety. On the analyst's part, he became more active in interpreting Mrs. C's defenses and recurrent relationship patterns over the course of the treatment. More recently, Halfon and Weinstein (2013) and Halfon, Fisek and Cavdar (2017) studied 30 sessions from the 70 studied by Jones and Windholz (1990) and found an improved capacity on the part of the patient to verbally express her emotions throughout her analysis.

These findings indicate that there was an increase in affective expression and elaboration in the case of study, however the specific types of interventions associated with this pattern have not been investigated. Literature has shown that transference interpretations impact outcome through increased insight that is combined with emotion expression in the here and now of the therapeutic relationship. Moreover, some studies show that in change moments, patient expresses more positive affect, whereas other studies show that there is initially negative affect expression. Expression of anger and sadness have most frequently been associated with transference work (i.e., Levy et al., 2006) that eventually gives way to more positive affect. Therefore, this study will examine the associations of transference interpretations on insight and positive and negative affect (anger and sadness) expression of the patient. Our specific hypotheses are: i) transference interpretations will be associated with an increase in emotional expression (positive emotions as well as anger and sadness), ii) transference interpretations will be associated with an increase in use of insight words.

\section{Methods}

\section{Case study}

The patient, Mrs. C, was a married woman in her late twenties. She was a social worker, and gave birth to two children throughout her 6 year-long psychoanalysis. She originally went to analysis with complaints of lack of sexual desire and pleasure, difficulty experiencing her feelings, being self-critical and uncomfortable disagreeing with others, and feeling tense and worried about her mistakes (Jones \& Windholz, 1990). The patient gave oral consent to be audiotaped as part of her regular, ongoing psychoanalytic treatment. The taping was done unobtrusively in the usual course of a five times per week psychoanalysis. 214 sessions of this patient's treatment have been published by Sage Press and were systematically deidentified. It is from this published de-identified data set that sampling for the present study was done.

\section{Session selection and segmentation}

Sessions were randomly selected over a span of general time period in the treatment from 70 sessions that were already studied in depth by other researchers (Bucci,
1997; Jones \& Windholz, 1990). Sessions 90 to 94 from the first year, Sessions 258 to 262 from the second year, Sessions 431 to 435 from the third year, Sessions 601 to 605 from the fourth year, Sessions 767 to 771 from the fifth year, and finally Sessions 936 to 940 from the sixth year of treatment were chosen.

Each session was divided into thematic units following the procedure developed by Waldron et al. (2004). This procedure allows the creation of units that take into consideration the turns of speech between the analyst and the patient. Specifically, thematic units consist of clinically meaningful segments of communication that aggregate around a given theme. This procedure yielded different number of units $(\min =6$ to $\max =24)$ between sessions ( $M=14.97, S D=4.55)$. To do the segmenting, two clinical psychology doctoral-level students were trained using the segmenting manual developed by Waldron et al. (2004). Afterwards, they segmented each session with an interrater reliability score of 0.83 . Disagreements were resolved upon discussion with the second author.

\section{Measures}

\section{Transference interpretations}

Each unit was scored based on the criteria provided by Transference Work Scale (Ulberg, Amlo, \& Hoglend, 2014). Ulberg et al. (2014) define transference interpretation as any intervention aimed to point out the therapistpatient relationship in the therapeutic process. Accordingly, there are five categories of transference interventions, which are not designed to be hierarchical: 1) addressing the transaction between the analyst and the patient, 2) encouraging the exploration of the thoughts and feelings about the therapy and analyst, 3 ) encouraging the exploration of how patient believes the analyst might think and feel about them, 4) including herself in the interpretation of internal dynamics and transference manifestations, and 5) providing genetic interpretation and linking this with therapeutic interaction. The scale has good interrater reliability for category classification, as kappa values range between 0.60 and 0.90 (Ulberg, Amlo, Critchfield, Marble, \& Hoglend, 2014). In the current study, the sessions were rated by three independent raters, a doctoral level clinical psychologist with over ten years of experience and two clinical psychology master's level students, who received ten hours of training from the first author. Interrater reliabilities between three independent raters were excellent ranging between 0.94 and 0.96 $(M=0.96, S D=0.01)$.Disagreements were resolved with consultation with the first author.

\section{Linguistic analyses}

The LIWC (Pennebaker et al., 2015a) is a computerassisted method for studying emotional, cognitive, and structural aspects of verbal and written speech. The LIWC compares transcripts to its dictionary, providing counts of 
words, as proportions of the total words analyzed within the transcript that tap into 66 various domains or word categories. The LIWC has been validated across a number of studies as detailed by Pennebaker, Chung, Ireland, Gonzales, and Booth (2007) with the psychological language categories related to health outcomes. In line with the aims of this study, we used LIWC word categories tapping into insightwords (think, know, realize, meaning, understand), positive emotions (love, fun, good, happy, gift, nice, sweet), sadness (crying, grief, sad) and anger (hate, kill, annoyed, rude) scores. Internal reliability coefficients are 0.84 for insight, 0.64 for positive emotion, 0.70 for sadness and 0.53 for anger categories (Pennebaker, Boys, Jordan, \& Blackburn, 2015b).

\section{Procedures and data analytic strategy}

In order to code for the type of intervention in each unit, a score of " 0 " was assigned if there was no intervention, "2" if analyst used any one of the transference interventions as described by above categories in TWS, and " 1 " for the remaining interventions that did not meet criteria for transference interventions. These non-transference interventions were analyst's activities that included explorations, clarifications and questions as well as nontransference interpretations such as addressing patient's conflicts (e.g., So you talked to your mother on the phone, What was your choice?, How do you feel it is connected? Well it's always been hard for you to imagine feeling opposite). All units (patient sections) were then entered into the LIWC2015 to calculate the percentage of insight words, positive emotion words, and sadness and anger words.

In our data psychotherapy units $(N=449)$ were nested within sessions $(N=30)$ who were nested within years $(N=6)$. Therefore, we used a multilevel modeling approach using MLwin Version 3 (Rasbash, Steele, Browne, $\&$ Goldstein, 2015). Since multiple sessions were conducted within the same year, we investigated the degree of interdependency due to years. We used two-level (units nested within sessions) and three level (units nested within sessions nested within years) empty multilevel models, where we entered our dependent variables, that were positive emotions, insight, anger and sadness with no predictor variables. The year level ICCs were $0.00, n s$., for positive emotions, insight, anger and sadness, which showed that years accounted for $0.00 \%$ of the variance in positive emotions, insight, anger and sadness suggesting that the variance in the dependent variables is not attributable to differences between years. The variance at the session level was slightly higher, albeit not significant for the dependent variables, such that the session level ICCs were 0.03 for positive emotions accounting for $0.45 \%$ of the variance, 0.00 for insight and sadness accounting for $0.00 \%$ of the variance, and 0.03 for anger accounting for $0.01 \%$ of the variance. Even though the session level variances were not significant, we chose to run two level models to control for the interdependency between units that may be attributable to session characteristics.

\section{Results}

\section{Quantitative results}

\section{Descriptive statistics}

The descriptive statistics and inter-correlations between the study variables are presented in Table 1. Table 2 shows the detailed descriptive statistics of the interventions. Over the course of the treatment, of the 226 analytic interventions, $43 \%$ of the analyst's interventions were non-transference type and 57\% were transference interpretations. The analyst's transference interventions increased over the course of treatment. When we look more closely at the types of transference interventions the analyst practiced, the analyst most frequently addressed the transaction between himself and the patient (Category 1; $44 \%$ ), followed by encouraging the exploration of the thoughts and feelings about the therapy and analyst (Category $2 ; 36 \%$ ), including himself in the interpretation of internal dynamics and transference manifestations (Category $4 ; 10 \%$ ) and the rest of the categories were practiced only a total of $10 \%$ of the time. The frequency of the categories practiced changed over the course of treatment such that in the first three years, the analyst mostly made Category 1 transference interventions, however after the third year, there was an increase in the Category 2 and 4 interventions.

Table 1. Descriptive Statistics and Pearson's Correlations for the Study Variables $(\mathrm{N}=442)$.

\begin{tabular}{|c|c|c|c|c|c|}
\hline & $\mathbf{M}$ & SD & Insight & Positive emotions & Anger \\
\hline Insight & 6.7 & 3.43 & - & - & - \\
\hline Positive emotions & 2.7 & 4.11 & $-.019 * *$ & - & - \\
\hline Anger & 0.35 & 0.62 & -0.05 & -0.04 & - \\
\hline Sadness & 0.13 & 0.34 & 0.01 & -0.02 & 0.01 \\
\hline
\end{tabular}

The difference between total number of interventions $(n=449)$ and study variables $(n=442)$ results from the fact that there were 7 incidents of therapist intervention where patient did not respond verbally, so there were no words to analyze. ${ }^{* *} \mathrm{P}<0.01$. 


\section{Multilevel modeling}

We conducted 4 separate fixed effect multilevel models with maximum likelihood (ML) estimation to analyze the data that nests change in units within the sessions, where positive emotions, insight, anger and sadness were our dependent variables and type of analyst's activity (transference intervention, non-transference intervention, no intervention) was our predictor. No intervention was the reference category.

The results indicated that (Table 3 ) both transference and non-transference interventions positively predicted positive emotions. Transference interventions positively predicted insight, and negatively predicted anger and sadness, whereas non-transference interventions were not significant in these models.

\section{Qualitative analyses}

The following segments were chosen according to patient's linguistic markers. We chose segments where there was a transference interpretation and an increase in one of the linguistic markers compared to the session mean.

\section{Year 1, session 93}

The patient talks about the difficult things she is facing in her life and reports that she feels uninvolved and unable to deal with these things. The analyst brings her attention to the transference:

Analyst: Including here. (category 1, address transaction)
Patient: ... instead of meeting them, I am running away from them.

Analyst: You said, ah, earlier that you've been feeling, I think you called it, uninvolved all week. I have a kind of an impression that that's the way you're feeling here, now. But I'm not sure. (category 1, address transaction)

Patient: ... And both weeks I've overslept a great deal, which I never, or very rarely do. And just somehow, as long as I'm in bed, asleep, then these things don't, whatever it is, don't bother me... (She elaborates further on her passivity, regressing into sleep to avoid facing difficulties). I was just thinking about the way I'm not feeling involved in anything today. And it's almost as if wherever I turn my thoughts to, I either have very ambivalent or confused or contradictory thoughts or feelings about different things so that I immediately withdraw from thinking about it, anything.

At this point, the patient expresses negative affect (feeling uninvolved, confused/ambivalent) outside of the transference valation; however, with the analyst's focus on the transference relationship, she brings up a transference reaction.

Patient: ... It's funny, something just occurred to me that, uhm, seems so little but now it seems that it could have thrown me for this whole time. When, when I came in today, I felt as if when I said hello to you that I looked at, looked at your eyes, really, longer than I ever had before. And I was sort of aware that I wasn't kind of hiding my face away from you as soon as I said hello, which I usually do. And then afterwards, I felt very, right when I

Table 2. Summary of analyst interventions in frequencies and percentages.

\begin{tabular}{lccccccc}
\hline Category & Total & Year 1 & Year 2 & Year 3 & Year 4 & Year 5 & Year 6 \\
\hline Non-Transference & $98(43 \%)$ & $24(53 \%)$ & $22(67 \%)$ & $22(45 \%)$ & $6(26 \%)$ & $11(42 \%)$ & $13(26 \%)$ \\
\hline Transference & $128(57 \%)$ & $21(29 \%)$ & $11(33 \%)$ & $27(55 \%)$ & $17(74 \%)$ & $15(58 \%)$ & $37(74 \%)$ \\
\hline Category I & $56(44 \%)$ & $15(71 \%)$ & $11(100 \%)$ & $12(44 \%)$ & $3(18 \%)$ & $6(40 \%)$ & $9(24 \%)$ \\
\hline Category II & $46(36 \%)$ & $4(19 \%)$ & 0 & $8(30 \%)$ & $9(53 \%)$ & $2(13 \%)$ & $23(62 \%)$ \\
\hline Category III & $10(8 \%)$ & $2(10 \%)$ & 0 & $4(15 \%)$ & $1(6 \%)$ & $2(13 \%)$ & $1(3 \%)$ \\
\hline Category IV & $13(10 \%)$ & 0 & 0 & $3(11 \%)$ & $3(18 \%)$ & $5(33 \%)$ & $2(5 \%)$ \\
\hline Category V & $3(2 \%)$ & 0 & 0 & 0 & $1(6 \%)$ & 0 & $2(5 \%)$ \\
\hline
\end{tabular}

Table 3. Summary of multilevel models predicting emotions and insight by type of intervention.

\begin{tabular}{|c|c|c|c|c|c|c|c|c|c|c|c|c|}
\hline \multirow[b]{2}{*}{ Intercept and predictors } & \multicolumn{3}{|c|}{$\begin{array}{c}\text { Model 1: } \\
\text { Positive emotions }\end{array}$} & \multicolumn{3}{|c|}{$\begin{array}{c}\text { Model 2: } \\
\text { Anger }\end{array}$} & \multicolumn{3}{|c|}{$\begin{array}{l}\text { Model 3: } \\
\text { Sadness }\end{array}$} & \multicolumn{3}{|c|}{$\begin{array}{l}\text { Model 4: } \\
\text { Insight }\end{array}$} \\
\hline & $\beta$ & $S E$ & t-Ratio & $B$ & $S E$ & $t$-Ratio & $\beta$ & $S E$ & $t$-Ratio & $\beta$ & $S E$ & $t$-Ratio \\
\hline Intercept $\left(\beta_{00}\right)$ & 2.08 & 0.29 & $7.17 * *$ & 0.42 & 0.05 & $8.4^{* *}$ & 0.14 & 0.02 & $7.00^{* *}$ & 6.59 & 0.23 & $28.65^{* *}$ \\
\hline Transference Interventions $\left(\beta_{10}\right)$ & 1.19 & 0.46 & $2.59 *$ & -0.15 & 0.07 & $-2.14 *$ & -0.07 & 0.03 & $-2.33^{*}$ & 0.50 & 0.18 & $2.77 *$ \\
\hline Non-Transference Interventions $\left(\beta_{20}\right)$ & 1.07 & 0.50 & $2.14^{*}$ & -0.14 & 0.08 & -1.75 & 0.05 & 0.04 & 1.25 & 0.04 & 0.42 & 0.09 \\
\hline
\end{tabular}

No intervention is the reference category. ${ }^{*} * \mathrm{P}<0.01 ; * \mathrm{P}<0.05$. 
came in, very uncomfortable that I had, well, it was in some way, exposed myself or made myself vulnerable.

Analyst: How would it make you vulnerable? (Category 2, thoughts and feelings about therapy)

Patient: I don't really think I understand how, except that I know I feel uncomfortable looking at people. Not always but very often I'm aware of sort of forcing myself to look at people because my inclination is not to.

Analyst: Were you aware of any particular thing you saw? (Category 3, beliefs about therapist)

Patient: When I looked at your eyes?

Analyst: Yeah. I mean, was there any more to it than that? (Category 3 cont.)

Patient: (Pause) Well, it was just sort of a friendly expression that, uhm, I don't know exactly what it was. But I think it's an expression I like to see and yet I feel uncomfortable if I see it and, and keep looking at it. (Pause)

She is now actively engaged and present as the analyst explores the transference and tries to keep the patient in the here-and-now by exploring her vulnerability in relation to himself. In response, even though the patient reports on her passivity in her outside relationships, she talks about being active with the analyst (looking him right in the eye) and the accompanying anxiety about exposing herself. She can elucidate these fears only after the analyst invites these responses in the transference relationship. Compared to the beginning of the session where she was talking about experiencing a general lack of involvement, she now shows increased self-focus, increased emotion that is more varied (feelings of discomfort and vulnerability) as well as positive affect (liking the analyst's friendly expression). She also shows insight into why she may be experiencing these feelings.

\section{Year 3, session 433}

This is one of the first sessions after the patient came back to analysis following the birth of her first child. She talks about her distance from her child, which helps her retrieve an important childhood memory:

Patient: (Pause) Well, something occurs to me, and then I'm puzzled about something that's been said today. What occurs to me is just that uhm, for a long time I found it very hard to speak of FSO (her child) by her name. (Pause) And it seemed like that came out of somehow, my keeping a distance from her emotionally. And I also found, just when my reaction to her being sick reminds me very much of what I always thought my family's was, or my parents' reaction was to my being sick, or any of us. That I don't know, it was as if there was a danger there of something happening to the child. So then you had to make up to the child for all the - maybe it, they were unexpressed things, but at least feelings that you had had-negative feelings.

In this segment, we start to understand patient's fears of expressing negative feelings, which may be related to hurting the other person (getting her child sick in this case) and the need to make up after such expressions, a pattern that she has inherited from her parents' reaction to her. At this point, the patient has a transference reaction:

Patient: I'm not sure which came first. But, uhm, I just suddenly felt you were laughing at me, and then I felt angry. (Pause)

Analyst: Why would you think I was laughing? (Category 3, beliefs about therapist)

Patient: (Pause) Well, I mean, it was partly the sound that you made just at that time. But it must be from what I was saying. (Sigh)

In the above unit, patient is able to express her anger towards the analyst. This is a significant turning point in that the patient's usual position had been one of passivity and avoiding her negative feelings possibly for fear of hurting others, an object-relational pattern that she had learned in her childhood. However, when the analyst invites her to reflect on her negative feelings, the patient, instead of avoiding or excusing her reaction, can elaborate on where her impression came from. In effect, we see increased self-focus and insight. Moreover, even though the patient expresses anger prior to the analyst's transference intervention, when the analyst invites her to reflect on her anger in reference to himself, she is able to think about where this feeling may have come from, linking it to what she had been saying earlier, which reduces her anger.

\section{Year 4, session 603}

Patient starts this session emotionally involved and engaged, disclosing transference material.

Patient: (5-Minute Silence) Mm, when I first came in I was thinking about the fact that today I (Clears throat) when I not only wore this dress, which I don't know if I think I look as nice in it as I used to, or if it, I feel the way it used to make me feel. But I st-, I think, I still was aware of uh, wanting to appear nice to you and, or, or aware of the fact you might be noticing how I look, or something like that...

Analyst: Why this special effort? (Category 2, thoughts and feelings about therapy)

Patient: Well I, th_this is when I started thinking about yesterday, and it seemed like it was almost (Sniff), well either, either that I was going back on an attitude I had yesterday, and, or I was trying to make up, sort of be nice to you after not being nice, or, er, for being late yesterday, or I don't know. But (Sniff, Sigh) I think somehow I felt very rebellious yesterday, and uhm, defiant, I think. I mean it seems like today I'm, I either got scared and I'm now saying that I'm really nice, or I'm denying something that I was feeling yesterday, or -

Analyst: What would you have gotten scared of? (Category 2, thoughts and feelings about therapy)

Patient: (Clears throat, Pause) Well I guess that you would disapprove, and uh show your disapproval by sort of withdrawing from me and being cold...But I remember sort of thinking of how you must be seeing $u$-, $u$-, what $I$ 
was saying, some of the things I said yesterday. And uhmAnalyst: Which was how? (Category 3, beliefs about therapist)

Patient: Well, that I'm sort of acting like a little child.(Sniff, Pause)

Analyst: This has a very familiar ring to it, I think, you know? It sounds to me like what you used to go through, or the way you at least talked about the way you went through things with your father. You'd show how angry you felt, and rebellious, and then ah, you must have done something very much like this, sort of back off and then feel contrite and want to sort of make amends. (Category 5 , repetitive interpersonal pattern)

In this session, we see that the patient repeats an archaic object relational pattern in the transference that is expressing her negative feelings or a rebellious attitude and then needing to be nice afterwards, and fearing that the analyst would disapprove of her anger and withdraw. When the analyst explores her transference reaction, the patient can elaborate on her fears, which in effect reduces her anger and fears of disapproval and paves the way for a genetic transference interpretation, linking her fears of expressing her anger with her childhood experiences with her father. Again, we see that as this experience is reenacted in the transference, and the analyst invites and explores the patient's reactions, the patient possibly feeling more contained, can focus on and show insight into her relational patterns, and face the negative feelings she has learned to avoid, which helps reduce their intensity.

\section{Year 5, session 767}

This session, the patient talks about a conflict she experiences with a friend. She expresses her anger towards him while they were playing bridge and refuses to play bridge with him again. Afterwards she feels very conflicted about what she has done. On the one hand she feels glad that she expressed her annoyance and ended the evening, on the other she feels guilty that she showed her anger. During the session, as she discusses her feelings regarding this conflict, she asks that her analyst say something to help her solve the conflict:

Patient: ... Uh, I was thinking back again to what to do about the BFMs (friends). And I think maybe I've had this feeling of I came here, uhm, and thought about it here ... I wanted you to just tell me something, or, if uhm, I hoped I'd think things here because of just thinking differently than I would if I were thinking it on my own, at home. But, because I think even when it was really bothering me before, and I kept thinking, I've got to do something right away, uhm, but then I didn't know what I wanted to do. And uhm, (sigh) I think I even thought then, well I can wait until after Monday, when I come here.

Analyst: Do you have anything in particular in mind that you wanted me to say? (Category 2, thoughts and feelings about therapy)

Patient: ... I, I guess what I was wondering is if I then want you to tell me why I was doing about that, or uhm.

There are two significant developments here; first the patient was able to express her annoyance/anger in a relationship outside of treatment, possibly with the help of the analysis where she was able to express her anger and see that she did not distance the analyst as she feared she would. Second, she openly seeks analyst's input to help her deal with the resulting feelings. She later reports that she finds this friend similar to her father, yet she was able to express her negative feelings by refusing to continue playing bridge and leaving their house. This is a new object-relational pattern that she was able to achieve via the repetitions and revisions of the old patterns in the transference relationship. Furthermore, unlike her usual avoidant attitude, she is openly asking her analyst to help her solve this internal conflict. The analyst's openness to explore these feelings with her further facilitates this process.

\section{Discussion}

The current study investigated the relationship between transference interpretations and the changes in level of insight, positive and negative affect expression in the patient's language in the course of a long-term psychoanalysis. The quantitative results showed that transference interpretations positively predicted patient's insight and positive affect expression. Contrary to our expectations, we found a negative association between transference interpretations, anger and sadness expression. Non-transference interventions, such as exploration of the patient's material, positively predicted positive emotions but was not significantly associated with other linguistic indicators. Qualitative analyses indicated that analyst's transference interventions helped the patient address her avoidance of negative emotions. The analyst's exploration and active interpretation of the transference helped the patient take a more active stance as she focused on and experienced these negative feelings that she had learned to avoid, and afterwards showed insight into why she may be experiencing these feelings. Patient was able to express her fears of hurting and distancing the analyst if she shows her anger and the need to make amends afterwards, an object-relational pattern that she had learned in her childhood. The analyst's open invitation to express her anger in relation to him possibly helped her feel more contained in the transference relationship, and form a more integrated image of the analyst as someone towards whom she can both express anger without fear of retaliation and feel supported. This further reduced negative affect and helped her bring more positive affect into her narrative. Towards the final year of the analysis, we saw that the patient was able to engage in new object relational patterns, carrying over what she had learned in the analysis to her outside relationships.

Before attempting to understand these findings in the light of current literature, we would like to comment on 
the relationship of this particular dyad, namely that of Mrs. $\mathrm{C}$ and her analyst. Analytic encounters are intersubjective, and insights gained through this process are specific to the particular patient and analyst dyad based on their particular subjectivities (Renik \& Spillius, 2004). Even though this case has been studied by various researchers, the focus has been on the patient and the analytic process, and very little has been said about the analyst. Jones and Windholz (1990) studies 10 sessions from each year (including all the sessions examined in the current study), and demonstrated that the analyst was able to accurately identify the patient's experience and emotional states, conveyed a neutral and non-judgmental attitude in the therapeutic process, and focused on the patient's feelings to help her get a deeper understanding of them. The results from the qualitative analysis of the sessions studies in the current study overlaps with these findings. We are not aware of any information regarding the experience of the analyst, but these results indicate that his attuned, non-judgmental and non-defensive therapeutic stance facilitated important changes in patient's psych.

The associations between transference interpretations, increased positive emotions and decrease in anger and sadness support a mechanism of change that has previously been found in transference focused therapies (e.g., Clarkin, Levy, \& Schiavi, 2005). The reactivation of object relational patterns in the transference, and the therapist's inviting and nonjudgmental attitude paves the way for experiencing these relational patterns and the concomitant affects in the transference. Afterwards, instead of attempting to deter the negative affect associated with self and other representations by educative means, transference interpretations, via encouraging the patient express negative affect towards the analyst in a non-judgmental context, and exploring of how patient believes the analyst might think and feel about them, helps form a more integrated and complex image of the analyst (i.e., someone whom the patient can get angry but won't retaliate, with whom anger can be expressed in the context of support and intimacy). In fact, our frequency analyses indicated that the analyst most frequently explored the patient's reactions in relation to himself and encouraged her to express thoughts and feelings relating to the analyst. Thus, eventually, overly negative self and other representations could be integrated with more positive representations, providing more balanced experiences and the opportunity to experience more positive feelings. In effect, it has previously been shown that transference interpretations are especially helpful in reducing anger as well as depression (Clarkin et al., 2007). Our findings also supported a decrease in anger and sadness in the sessions. Moreover, the increase in positive emotions point to a broadening in the patient's experience, which has been found to develop within the context of an emotionally attuned and containing relationship with the therapist (Stalikas, Fitzpatrick, Mistkidou, Boutri, \& Seryianni, 2015).
It is important to note that even though non-transference interpretations, such as exploration were also associated with increased positive emotions, it was only transference interpretations that reduced negative affect expression, further supporting their importance in the containment of negative affect and its neutralization in the context of more integrated and complex object relations. The patient, using the transference relationship as a starting point, was able reflect on similar situations (i.e., dinner party) where she had difficulty expressing her anger and the following anxiety.

This sort of increase in insight and cognitive-affective processing was recently validated in a randomized controlled trial that showed that individuals who were diagnosed with borderline personality disorder and received Transference-Focused Psychotherapy (TFT) had a significant increase in their reflective function (Fischer-Kern et al., 2015). Another randomized controlled trial also showed evidence for the improvement in reflective function as a result of TFT (Levy et al., 2006). Furthermore, there is evidence showing that insight mediates the link between transference and improvement at the end of treatment (Johansson et al., 2010). Future research can investigate the changes in the patient's reflective function as they occur in the sessions.

It is important to note that the aforementioned findings from transference focused therapies measure global changes in insight and affect at outcome mostly via observer rated interviews. To the author's knowledge, these results are the first to show an association between transference interpretations, insight and emotion expression within the sessions. Even though it was initially predicted that transference interventions would be associated with increased emotion expression, following findings of Høglend and Hagtvet (2019), our findings indicated that patient's negative affect decreased in the context of transference interpretations, possibly due to the analyst's emotional containment. As stated before, our qualitative findings indicated that the analyst's invitation of the patient's negative emotional responses in the transference helped decrease patient's avoidance of the negative feelings and process them with insight. Even though we were not able to perform lagged-analyses to test such results, future research can test whether transference interventions practiced one lag before patient's expression of insight and emotion expression cause changes in affect experiencing, which predict global changes in affect expression and tolerance at the end of treatment.

These findings also support a recent study that found that negative relationship patterns that the patients unconsciously repeats without awareness, particularly more aggressive and less supportive patterns both within and outside the transference relationship may impede with the therapeutic bond and patient's progress in treatment (Hegarty, Marceau, Gusset, \& Grenyer, 2019). These patterns need to be addressed early in treatment for increased 
therapeutic gains and evocation of positive experiences. Mergenthaler (2008) found that there is initially evocation of negative emotion associated with negative experiences followed by an increase in positive emotion associated with problem solving. Temporal causal associations cannot be derived from this study, and future research is necessary to investigate whether transference interpretations, particularly interpretation of negative relational patterns early in treatment predicts later improvements in affect expression, specifically an increase in positive affect and whether insight mediates these changes.

\section{Clinical and research implications}

On the basis of the results from the current study, transference interpretations with an emphasis on the hereand-now are essential elements of change in psychoanalytic treatment. An open attitude that invites for open discussion of uncomfortable feelings, e.g., anger and sadness, in the here-and-now context will facilitate linking negative and positive aspects of object relations leading to a more integrated view of both self and others (Kernberg, 2016).

We were not able to assess whether specific kinds of transference interpretations were more conducive in generating insight and emotional processing, however, our frequency analyses indicated that the analyst most frequently explored the transaction between himself and the patient (Category 1 ) followed by encouraging the exploration of the thoughts and feelings about the therapy and analyst (Category 2), and these were most frequently practiced in the initial years of the psychoanalysis. This may have been especially containing for this patient, rather than more interpretative interventions such as genetic interpretations in the first years, allowing her to feel safe to express disturbing experiences in the here and now of the transference. Consistent with this finding, Hoglend, Gabbard, and Gabbard (2012), in a literature review point out that most transference interpretations do not use linking of current-past object relations. As a matter of fact, Levy and Scala (2012) suggests that linking here-and-now transference reactions with past relationships is not necessarily needed, and sometimes specifically not recommended, because such linking may be disorganizing for some patients, particularly for those with personality disorders. Future research can specifically examine which kinds of transference interpretations are associated with an increase in insight and emotion expression.

This study has significant implications for psychotherapy process research. Our study is the first, to our knowledge, to show evidence for a link between transference interpretations and therapy process variables using linguistic measures. More specifically, the results demonstrated that the effects of transference interpretations on insight and affective expression within the sessions can be successfully measured by analyzing the fluctuations evidenced in the language use of the patient. If narrating upsetting/traumatizing experiences is considered as an emotion regulation strategy, then linguistic measures used to examine particular language patterns within sessions can be a useful approach in psychotherapy process research. This study suggests that the micro-analysis of the language style used in the interaction between the patient and therapist is conducive in identifying the immediate affective and cognitive changes in the context of treatment interventions.

\section{Limitations and directions for future research}

Some limitations of this study has to be considered. First, even though in depth analysis of single case studies are instrumental in therapy process research, drawing general conclusions based on a single case poses a major limitation. The second area of concern with the data set is its small size. An improved methodology would be based on a repeated single case design, preferably with more time points, involving relatively large sample of treatments for adequate comparison. Another limitation is the lack of outcome measures to evaluate the effectiveness of this treatment. The archival nature of this data prevented current researchers to assess the outcome of this treatment using reliable and valid instruments. Furthermore, even though we were able to document that transference interpretations predict linguistic changes, we are not able to tell whether the patient is able to practice this capacity outside of the therapy situation, and directly link these to measures of symptom assessment. Another area of concern is related to the measurement of insight. Insight was measured using a computer program that analyzes words and categorizes them as insight words. This approach does not take independent judgment of the therapist or observers regarding improvement in the level of patient insight into consideration. An alternative method would be to utilize computer aided program together with a well-established measure of insight, e.g., insight scale completed by independent judges. In a similar vein, we did not assess non-verbal affect expression, which could have yielded a different relationship between transference interpretations and negative affect expression. Future research can overcome this limitation by utilizing assessment instruments to evaluate both verbal and non-verbal affect expression. Furthermore, we were not able to account for other individual factors or therapy variables (i.e., alliance) that may have affected the course of treatment. Future studies can also apply other measures of process to understand core therapist factors and therapeutic interaction that aid in the development of insight and affect expression.

\section{Conclusions}

This study sought to put forth an empirical model that could be used to deepen our understanding of salient forces such as transference interpretations, insight, and af- 
fect expression in a long-term psychoanalysis. Empirical studies in this context are necessary to test the psychoanalytic model using multiple perspectives that involve quantitative ratings of the clinical material, fine-grained linguistic measures as well as a qualitative illustrations based on the authors' clinical impressions to further psychoanalytic knowledge and technique.

\section{References}

Ablon, J. S. \& Jones, E. (2005). On analytic process. Journal of the American Psychoanalytic Association, 53, 541-568. doi: 10.1177/00030651050530020101

Aron, L. (2006). Analytic impasse and the third: Clinical implications of intersubjectivity theory. International Journal of Psychoanalysis, 87, 349-368. doi: 10.1516/15EL-284Y7Y26-DHRK

Benjamin, J. (1990). An outline of intersubjectivity: The development of recognition. Psychoanalytic Psychology, 7S, 3346. doi: $10.1037 / \mathrm{h} 0085258$

Bucci, W. (1997). Patterns of discourse in "good" and troubled hours: A multiple code interpretation. Journal of the American Psychoanalytic Association, 45, 155-187. doi: 10.1177/00030651970450010301

Bucci, W. \& Maskit, B. (2007). Beneath the surface of the therapeutic interaction: The psychoanalytic method in modern dress. Journal of American Psychoanalytic Association, 55, 1355-1397. https://doi.org/10.1177/000306510705500412

Bucci, W., Maskit, B., \& Hoffman, L. (2012). Objective measures of subjective experience: The use of therapist notes in process-outcome research. Psychodynamic Psychiatry, 40(2), 303-340. doi: 10.1521/pdps.2012.40.2.303

Bucci, W., Maskit, B., \& Murphy, S. (2016). Connecting emotions and words: The referential process. Phenomenology \& the Cognitive Sciences, 15(3), 359-383. doi: 10.1007/s11097-0159417-z

Buchheim, A. \& Mergenthaler, E. (2000). The relationship among attachment representations, emotion-abstraction patterns, and narrative style: A computer-based text analysis of the adult attachment interview. Psychotherapy Research, 10(4), 390-407. doi: $10.1093 / \mathrm{ptr} / 10.4 .390$

Clarkin, J. F., Levy, K. N., Lenzenweger, M. F., \& Kernberg, O. F. (2007). Evaluating three treatments for borderline personality disorder: A multiwave study. The American Journal of Psychiatry, 164(6), 922-928. doi: 10.1176/ajp.2007.164.6.922

Clarkin, J. F., Levy, K. N., \& Schiavi, J. M. (2005). Transference focused psychotherapy: Development of a psychodynamic treatment for severe personality disorders. Clinical Neuroscience Research, 4(5-6), 379-386. doi: 10.1016/j.cnr.2005. 03.003

Cooper, A. M. (1987). Changes in psychoanalytic ideas: Transference interpretation. Journal of the American Psychoanalytic Association, 35(1), 77-98. doi: 10.1177/000306518703 500104

Doering, S., Hörz, S., Rentrop, M., Fischer-Kern, M., Schuster, P., Benecke, C., ... Buchheim, P. (2010). Transference-focused psychotherapy v. treatment by community psychotherapists for borderline personality disorder: Randomized controlled trial. The British Journal of Psychiatry, 196(5), 389-395. doi: 10.1192/bjp.bp.109.070177

Fisher, H., Atzil-Slonim, D., Barkalifa, E., Rafaeli, E., \& Peri,
T. (2016). Emotional experience and alliance contribute to therapeutic change in psychodynamic therapy. Psychotherapy, 53(1), 105-116. doi: 10.1037/pst0000041

Fisher-Kern, M., Doering, S., Taubner, S., Hörz, S., Zimmerman, J., Rentrop, M., ... Buchheim, A. (2015). Transferencefocused psychotherapy for borderline personality disorder: Change in reflective function. The British Journal of Psychiatry, 207(2), 172-174. doi: 10.1192/bjp.bp.113.143842

Gabbard, G. O. \& Westen, D. (2003). Rethinking therapeutic action. The International Journal of Psychoanalysis, 84(4), 823-841. doi: 10.1516/N4T0-4D5G-NNPL-H7NL

Gay, P. (1988). Therapy and technique: A handbook for technicians. In P. Gay (Ed.), Freud: A life of our time (pp. 292305). New York: W. W. Norton \& Company.

Gelo, O. C. G. \& Mergenthaler, E. (2012). Unconventional metaphors and emotional-cognitive regulation in a metacognitive interpersonal therapy. Psychotherapy Research, 22(2), 159-175. doi: 10.1080/10503307.2011.629636

Grande, T., Rudolf, G., Oberbracht, C., \& Pauli-Magnus, C. (2003). Progressive changes in patients' lives after psychotherapy: Which treatment effects support them? Psychotherapy Research, 13(1), 43-58. doi: 10.1093/ptr/kpg006

Halfon, S., Fisek, G., \& Cavdar, A. (2017). An empirical study of verb use as indicator of emotional access in therapeutic discourse. Psychoanalytic Psychology, 34(1), 35-49. doi: 10.1037/pap0000081

Halfon, S. \& Weinstein, L. (2013). From compulsion to structure: An empirical model to study invariant repetition and representation. Psychoanalytic Psychology, 30, 394-422. DOI: $10.1037 / \mathrm{a} 0033618$

Heimann, P. (1956). Dynamics of transference interpretations. International Journal of Psychoanalysis, 37, 303-310.

Hegarty B., Marceau E. M., Gusset M., \& Grenyer B. (2019). Early treatment response in psychotherapy for depression and personality disorder: links with core conflictual relationship themes, Psychotherapy Research, Online First. doi: 10.1080/10503307.2019.1609114

Hoglend, P. (1993). Transference interpretations and long-term change after dynamic psychotherapy of brief to moderate lenght. The American Journal of Psychotherapy, 47(4), 494507. doi: 10.1176/appi.psychotherapy.1993.47.4.494

Hoglend, P. (2004). Analysis of transference in psychodynamic psychotherapy: A review of empirical research. Canadian Journal of Psychoanalysis, 12(2), 279-300.

Hoglend, P., Gabbard, G. O, \& Gabbard, G. O. (2012). When is transference work useful in psychodynamic psychotherapy? A review of empirical research. In R. Levy, J. Ablon, \& H. Kachele (Eds.), Psychodynamic Psychotherapy Research. Current Clinical Psychiatry. Totowa, NJ: Humana Press. doi: 10.1007/978-1-60761-792-1 26

Hoglend, P. \& Hagtvet, K. (2019). Change mechanisms in psychotherapy: Both improved insight and improved affective awareness are necessary. Journal of Consulting and Clinical Psychology, 87(4), 332-344. doi: 10.1037/ccp0000381

Johansson, P., Hoglend, P., Ulberg, R., Amlo, S., Marble, A., Bogwald, K.-P., ... Heyerdahl, O. (2010). The mediating role of insight for long-term improvements in psychodynamic therapy. Journal of Consulting and Clinical Psychology, 78(3), 438-448. doi: 10.1037/a0019245

Jones, E. E. \& Windholz, M. (1990). The psychoanalytic case study: Toward a method for systematic inquiry. Journal of American Psychoanalytic Association, 38, 985-1015. doi: /10.1177\%2F000306519003800405 
Kernberg, O. F. (2016). New developments in transference focused psychotherapy. The International Journal of Psychoanalysis, 97(2), 385-407. doi: 10.1111/1745-8315.12289

Kernberg, O. F., Diamond, D., Yeomans, F. E., Clarkin, J. F., \& Levy, K. N. (2008). Mentalization and attachment in borderline patients in transference focused psychotherapy. In E. L. Jurist, A. Slade, \& S. Bergner (Eds.), Mind to mind: Infant research, neuroscience, and psychoanalysis (pp. 167-201). New York, NY, US: Other Press.

Kivligham, D. M., Jr., Multon, K. D., \& Patton, M. J. (2000). Insight and symptom reduction in time-limited psychoanalytic counseling. Journal of Counseling Psychology, 47(1), 50-58. doi: 10.1037/0022-0167.47.1.50

Kramer, U., Pascual-Leone, A., Despland, J.-N., \& de Roten, Y. (2015). One minute of grief: Emotional processing in shortterm dynamic psychotherapy for adjustment disorder. Journal of Consulting and Clinical Psychology, 83(1), 187-198. doi: $10.1037 / \mathrm{a} 0037979$

Lepper, G. \& Mergenthaler, E. (2008). Observing therapeutic interaction in the "Lisa" case. Psychotherapy Research, 18(6), 634-644. doi: 10.1080/10503300701442001

Levitt, H. M. \& Piazza-Bonin, E. (2011). Therapists' and clients' significant experiences underlying psychotherapy discourse. Psychotherapy Research, 21(1), 70-85. doi: 10.1080/10503307.2010.518634

Levy, K. N., Meehan, K. B., Kelly, K. M., Reynoso, J. S., Weber, M., Clarkin, J. F., \& Kernberg, O. F. (2006). Change in attachment patterns and reflective function in a randomized control trial of transference-focused psychotherapy for borderline personality disorder. Journal of Consulting and Clinical Psychology, 74(6), 1027-1040. doi: 10.1037/0022-006X.74.6.1027

Levy, K. N. \& Scala, J. W. (2012). Transference, transference interpretations and transference-focused therapies. Psychotherapy, 49(3), 391-403. doi: 10.1037/a0029371

Lieberman, M. A. \& Goldstein, B. A. (2006). Not all negative emotions are equal: The role of emotional expression in online support group for women with breast cancer. PsychoOncology, 15, 160-168. doi: 10.1002/pon.932

Mergenthaler, E. (2008). Resonating minds: A school-independent theoretical conception and its empirical application to psychotherapeutic processes. Psychotherapy Research, 18(2), 109-126. doi: 10.1080/10503300701883741

Messer, S. B. (2013). Three mechanisms of change in psychodynamic therapy: Insight, affect, and alliance. Psychotherapy, 50(3), 408-412. doi: 10.1037/a0032414

Messer, S. B., \& McWilliams, N. (2007). Insight in psychodynamic therapy: Theory and assessment. In L. G. Castonguay \& C. Hill (Eds.), Insight in psychotherapy (pp. 9-29). Washington, DC, US: American Psychological Association.

Mitchell, S. (1988). Introduction. In Relational concepts in psychoanalysis (pp. 1-12). Cambridge, MA: Harvard University Press.

Pennebaker, J. W., Booth, R. J., Boyd, R. L., \& Francis, M. E. (2015). Linguistic inquiry and word count: LIWC2015. Austin, TX: Pennebaker Conglomerates. Retrieved from: www. LIWC.net

Pennebaker, J. W., Boyd, R. L., Jordan, K., \& Blackburn, K. (2015). The development and psychometric properties of LIWC2015. Austin, TX: University of Texas at Austin.

Pennebaker, J. W., Chung, C. K., Ireland, M., Gonzalez, A., \& Booth, R. J. (2007). The development and psychometric properties of LIWC2007. Retrieved from: www. LIWC.net
Pennebaker, J. W. \& Francis, M. E. (1996). Cognitive, emotional, and language processes in disclosure. Cognition and Emotion, 10(6), 601-626. doi: 10.1080/026999396380079

Pennebaker, J. W., Mayne, T. J., \& Francis, M. E. (1997). Linguistic predictors of adaptive breavement. J. of Personality and Social Psychology, 32(4), 863-871. doi: 10.1037//00223514.72.4.86

Pennebaker, J. W. \& Seagal, J. D. (1999). Forming a story: The health benefits of narrative. Journal of Clinical Psychology, 55(10), 1243-1254. doi: 10.1037//0022-3514.72.4.86

Piper, W. E., Azim, H. F. A., Joyce, A. S., \& McCallum, M. (1991). Transference interpretations, therapeutic alliance, and outcome in short-term individual psychotherapy. Archives of General Psychiatry, 48(10), 946-953. doi: 10.1001/archpsyc.1991.01810340078010

Rasbash, J., Steele, F., Browne, W. J., \& Goldstein, H. (2015). A user's guide to MLwiN, version 3.00. Bristol, UK: University of Bristol.

Renik, O. \& Spillius, E. B. (2004). Psychoanalytic controversies: Intersubjectivity in psychoanalysis. The International Journal of Psychoanalysis, 85(5), 1053-1064. doi: 10.1516/Q15V-JC04-T4HG-XP4D

Solbakken, O. A., Hansen, R. S., \& Monsen, J. T. (2011). Affect integration and reflective function: Clarification of central conceptual issues. Psychotherapy Research, 21(4), 482-496. doi: 10.1080/10503307.2011.583696

Stalikas A., Fitzpatrick M., Mistkidou P., Boutri A., \& Seryianni C. (2015). Positive emotions in psychotherapy: conceptual propositions and research challenges. In O. Gelo, A. Pritz, \& B. Rieken (Eds.), Psychotherapy research (pp. 331-349). Vienna: Springer.

Ulberg, R., Amlo, S., Critchfield, K. L., Marble, A., \& Høglend, P. (2014). Transference interventions and the process between therapist and patient. Psychotherapy. Advance online publication. doi: 10.1037/a0034708

Ulberg, R., Amlo, S., \& Hoglend, P. (2014). Manual for transference work scale; a micro-analytical tool for therapy process analyses. BMC Psychiatry, 14, 291-304. doi: 10.1186/s12888-014-0291-y

Ulberg, R., Amlo, S., Johnsen Dahl, H.-S., \& Hoglend, P. (2017). Does insight mediate treatment and enhance outcome? Psychoanalytic Inquiry, 37(3), 140-152. doi: 10.1080/ 07351690.2017.1285184

Valdes, N., Dagnino, P., Krause, M., Perez, J. C., Altimir, C., Tomicic, A., \& de la Parra, G. (2010). Analysis of verbalized emotions in the psychotherapeutic dialogue during change episodes. Psychotherapy Research, 20(2), 136-150. doi: 10.1080/10503300903170921

Valdes Sanchez, N. (2012). Analysis of verbal emotional expression in change episodes and throughout the psychotherapeutic process: Main communicative patterns used to work on emotional contents. Clinica y Salud, 23(2), 153-179. doi: 10.5093/cl2012a10

Vegas, M., Halfon, S., Cavdar, A., \& Kaya, H. (2015). When interventions make an impact: An empirical investigation of analyst's communications and patient's productivity. Psychoanalytic Psychology, 32(4), 580-607. doi: 10.1037/ a0039020

Waldron, S., Scharf, R. Coures, J. Firestein, S. K., Burton, A., \& Hurst, D. (2004). Saying the right thing at the right time: A view through the lens of the Analytic Process Scales (APS). The Psychoanalytic Quarterly, 73(4), 1079-1125. doi: 10.1002/j.2167-4086.2004.tb00193.x 